\title{
AN INDUCTION SENSOR FOR MEASURING CURRENTS OF NANOSECOND RANGE
}

Purpose. A current meter based on the principle of electromagnetic induction is designed to register the current flowing in the rod lightning. The aim of the article is to describe the way of increasing the sensitivity of the converter by means of their serial communication. Methodology. The recorded current is in the nanosecond range. If compared with other methods, meters based on the principle of electromagnetic induction have several advantages, such as simplicity of construction, reliability, low cost, no need in a power source, relatively high sensitivity. Creation of such a meter is necessary, because in some cases there is no possibility to use a shunt. Transient properties of a meter are determined by the number of turns and the constant of integration. Sensitivity is determined by measuring the number of turns, the coil sectional area, the core material and the integration constant. For measuring the magnetic field pulses with a rise time of $5 \mathrm{~ns}$ to $50 \mathrm{~ns}$ a meter has turns from 5 to 15. The sensitivity of such a meter is low. When the number of turns is increased, the output signal and the front increase. Earlier described dependencies were used to select the main parameters of the converter. It was based on generally accepted and widely known equivalent circuit. The experience of created earlier pulse magnetic field meters was considered both for measuring the magnetic fields, and large pulse current. Originality. Series connection of converters has the property of a long line. The level of the transient response of the meter is calculated. The influence of parasitic parameters on the type of meter transient response is examined. The shown construction was not previously described. Practical value. The results of meter implementation are given. The design peculiarities of the given measuring instruments are shown. References 6, figures 9.

Key words: magnetic field strength, corona current, surge characteristic, electromagnetic induction, bi-exponential pulse, induction transformer's calibration, distributed parameter line.

Представлены результаты реализации высокочувствительного датчика токов наносекундного диапазона индукционного типа для измерения импульсов тока, протекающих на стержневом молниеприемнике. Проведен анализ современных достижений в области измерений слабых импульсных токов. Представлены результаты расчета датчика, показано влияние паразитных параметров на вид переходной характеристики датчика. Описаны основные особенности конструкции. Приведены параметры созданного датчика и результаты калибровки. Библ. 6 , рис. 9 .

Ключевые слова: напряженность магнитного поля, ток короны, переходная характеристика, электромагнитная индукция, биэкспоненциальный импульс, калибровки индукционного преобразователя, линия с распределенными параметрами.

Introduction. Knowledge of the gas discharge area are used in various fields of modern science. Corona discharge occurs in strongly inhomogeneous electric fields characteristic for electrode systems «needle-plane». The effect occurs at applying potential of certain value required for the implementation of self-discharge form. There is a voltage range in which the discharge current is a stable pulse sequence. Increasing the voltage across the discharge gap, while not changing external conditions, is leading to the increase in the pulse repetition frequency. Today at the Scientific-\&-Research Planning-\&-Design Institute «Lightning» of the NTU «KhPI» they are working on the study of corona discharge from lighting receivers in the ominous atmosphere. The results will create a warning system of thunderstorm danger. To register the discharge current flowing in the needle electrode an inductive transducer is used. As on the stationary rod electrodes it is impossible to install a shunt, the inductive transducer in this case is an indispensable tool which does not need electrical contact with the lightning receiver.

The goal of the paper is the creation of measurement system which will be the basis for a thunderstorm hazard warning system.

Problem definition. Modeling of process of the corona of rod lightning receivers is carried at a highvoltage test bench BBC-1.2 of the Scientific-\&-Research Planning-\&-Design Institute «Lightning» of the NTU «KhPI». Lightning receiver is placed between two parallel metal planes. Dimensions of planes: lower $-4.02 \times 6.56$ $\mathrm{m}$, upper $-3.63 \times 5.22 \mathrm{~m}$. The lower plane is grounded, the upper plane is potential. The rod was placed on the bottom plane and has a connection with grounded plane through a shunt resistance of $75 \Omega$. An induction converter allowed to galvanically separate the measuring system from installation components under a high potential.

Typical waveforms of the measured current are shown in Fig. 1.

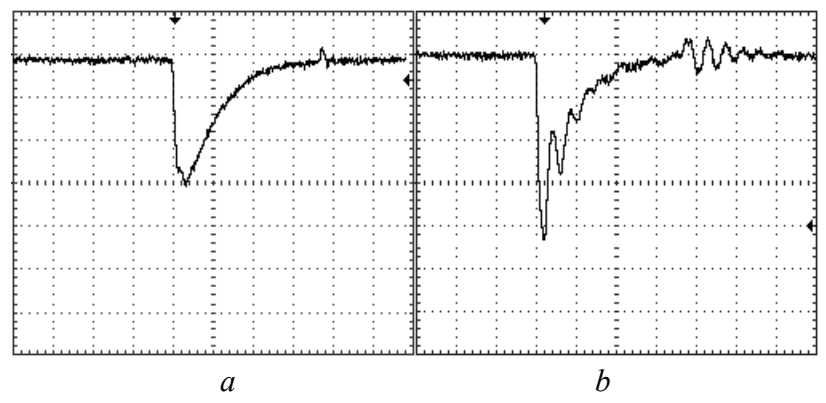

Fig. 1. Typical waveforms of current of the unit streamer (vertical scale $-100 \mathrm{mV} /$ cell; horizontal scale -100 $\mathrm{ns} /$ cell)

For different values of the electric field strength in the space and, depending on the geometry of the structure, changes of the amplitude-temporal parameters of the 
current of the streamer are possible but they are within a certain range: the current pulse rise time of $14.8 \mathrm{~ns}$ to 20.5 ns, amplitude - from $4 \mathrm{~mA}$ to $20.5 \mathrm{~mA}$.

Formulae for calculating the rise time of the transient response, the meter constant of integration at using $R L$-integrator and transducer sensitivity are of the form $[2,3]$ :

$$
\begin{gathered}
T_{\text {riseTime }}=3,35 \sqrt{L_{d} C_{d}} ; \\
T=\frac{L_{d}}{R_{I}} ; \\
K_{n}=\frac{\mu_{o} \mu_{r} S w \cdot \cos \varphi}{T},
\end{gathered}
$$

where $T_{\text {riceTime }}$ is the rise time of the transient response; $L_{d}$ is the inductance of the inductive transducer; $C_{d}$ is the total parasitic capacitance; $T$ is the constant of integration of the itself integrating inductive transducer; $R_{I}$ is the sum of own and integrating resistance; $K_{n}$ is the conversion factor; $\mu_{0}$ is the magnetic permeability constant; $\mu_{r}$ is the magnetic permeability of the core material; $S$ is the turns area; $w$ is the turns number; $\varphi$ is the angle between the magnetic field strength vector and the normal to the frame.

To ensure reliable registration of streamer current, measuring sensitivity is taken not less than $2.5 \mathrm{mV}$ per $1 \mathrm{~mA}$.

1. Analysis of the latest achievements in the field of measuring the pulsed currents. In [2] the meter of high pulsed currents for measuring in circuits with high operating voltage and the absence of the possibility of using a shunt is described. A schematic diagram of the meter is shown in Fig. 2. The design is illustrated in Fig. 3.

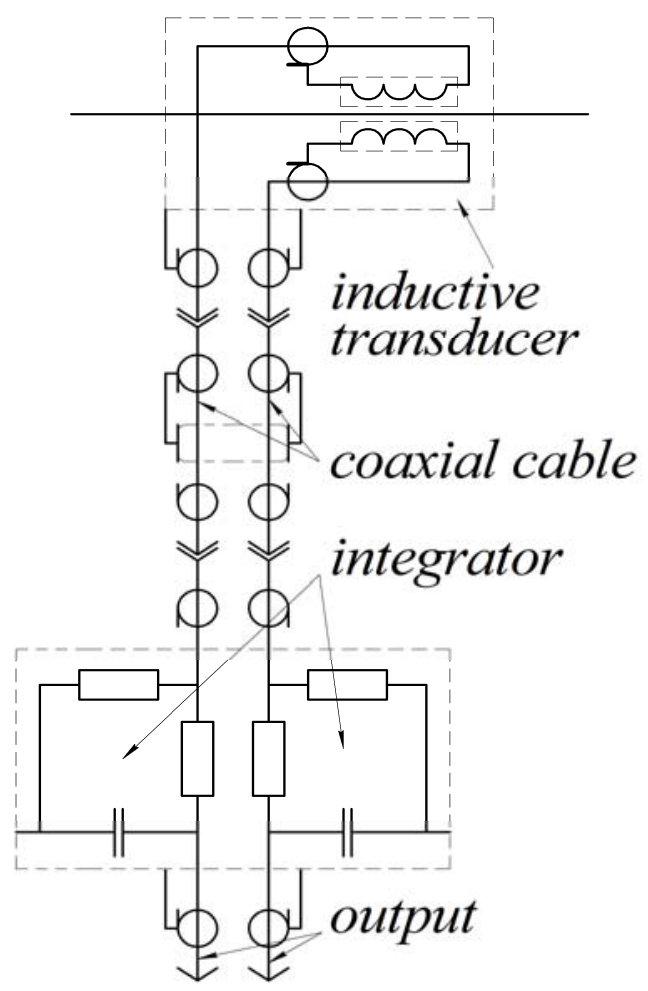

Fig. 2. A schematic diagram of the meter

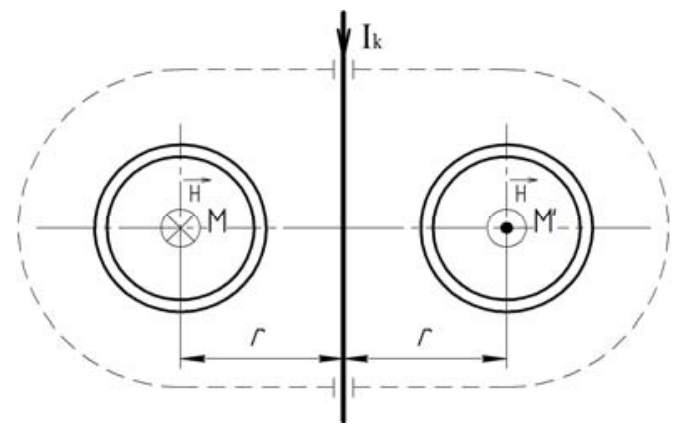

Fig. 3. Design of the meter

The signal is integrated on the $R C$-integrator. Measured current $I_{k}$ is passed along a straight conductor. Around the conductor the magnetic field is generated that coincides in shape with the current pulse. In symmetric with respect to the conductor points $\mathrm{M}$ and $\mathrm{M}^{\prime}$ coplanar and in opposite phase two inductive measuring transducers are installed.

The entire construction is enclosed in an electromagnetic shield of cylindrical shape. At the electromagnetic field action in both converters equal in magnitude but opposite in phase EMF occur that in subsequent devices are integrated and then subtracted in the differential amplifier of the oscilloscope. Developed design can effectively get rid of the noise.

In [4] the results of the development of tools for measuring pulsed magnetic fields of electric discharge facilities used to test hardware on the lighting resistance are presented. The theory of operation of pulsed magnetic fields meters of induction type is described. The requirements for meter's parameters for reliable measurement of bi-exponential fields are presented. The meter's parameters shall be as follows:

$$
\begin{gathered}
T_{\text {inc }} \geq(3 \div 5) T_{\text {riseTime }} ; \\
T_{\text {dec }} \geq(10 \div 50) T_{\text {fallTime }},
\end{gathered}
$$

where $T_{\text {fallime }}$ is the fall time of the transient responce; $T_{i n c, d e c}$ is the front time and fall time of the measured magnetic field pulses.

To measure the broadband pulsed magnetic fields a measuring circuit consisting of two independent channels: wave front measurement and a channel of the pulse width measurement is described. A schematic diagram is shown in Fig. 4.

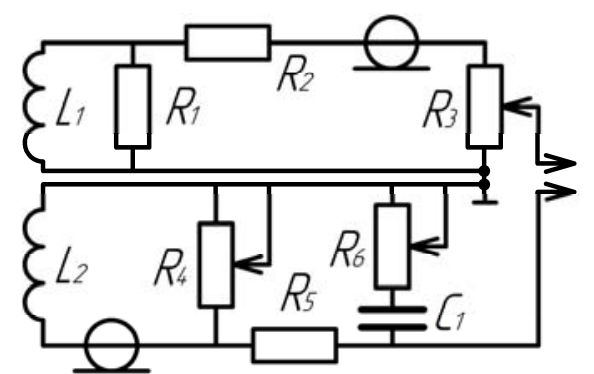

Fig. 4. Circuit of the broadband magnetic field strength meter

The wave front measurement channel reliably measures the shape of the pulse in the time range from nanoseconds to $10 \mu \mathrm{s}$, and the fall measurement channel in the time range from $10 \mu$ s to several tens of 
milliseconds. To integrate the signal they use $R L$ (elements $L_{l}, R_{l}$ ) and $R C$ (elements $R_{5}, C_{l}$ ) integrators. Elements $L_{1}$ are $L_{2}$ are the inductance of the front and fall measurement channels. For proper operation of the meter it is necessary to achieve matching shapes of signals on the fall of the pulse front measuring channel and the pulse front of the measuring channel of the fall. This is achieved by adjusting $R_{4}$. Regulation of signal amplitude from the front channel measurement is performed by resistor $R_{3}$. At the signals summation there is a signal failure at the joint of signals which eliminates by the adjustable of $R_{6}$. Resistor $\mathrm{R} 2$ allows to align the cable. In [5] a broadband meter of the magnetic field strength is implemented.

In [6] the principle of operation, productivity, limitations and development of current measurement technology using the Rogowski coil are considered and measures to improve the design of the integrator which allows for bandwidth up to $10 \mathrm{MHz}$ are presented. The analysis of the behavior of the Rogowski coil at high frequency currents measurements is carried out. A simplified equivalent circuit of the Rogowski coil is shown in Fig. 5.

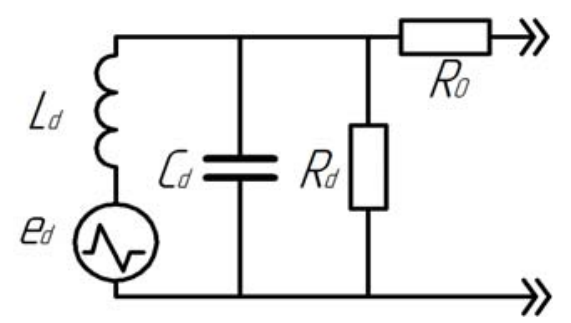

Fig. 5. An electrical equivalent circuit of the coil with loading resistance $R_{d}$ and series resistor $R_{0}\left(R_{0}>>R_{d}\right)$

Elements $L_{d}$ are $C_{d}$ are the inductance and capacitance of the coil, $R_{0}$ is the integrating resistance. To provide the necessary attenuation the selection of $R_{d}$ is carried out in accordance with the expression:

$$
R_{d}=\frac{\pi}{2} \sqrt{\frac{L_{d}}{C_{d}}} .
$$

$R_{d}$ value is higher than the characteristic impedance of the coil $\rho=(L / C)^{0,5}$ although there is reason to assume that the coil should be loaded on $\rho$. But it was found that (6) gives the best transient response. Moreover, the measuring cable capacitance will increase the equivalent capacitance of the coil and thus significantly reduce throughput. To avoid this effect, the series resistance R0 is set at the end of the coil as shown in Fig. 5. This resistor forms part of a $R C$ integrator [6].

2. Description of the sensor's design. The meter consists of series-connected inductive transducers, as shown in Fig. 6. The output signal increases in proportion to the number of connected meters if the system has the property of a long line. This occurs when the measuring field wavelength is comparable to the electrical length of the coil's conductor. Selection of resistance $R_{d}$ can be performed in accordance with (6) but the sensor operates in an oscillating mode. Fig. 7 shows the results of calculation of the transient response at the value $\rho$ of the coil equal to $160 \Omega$.

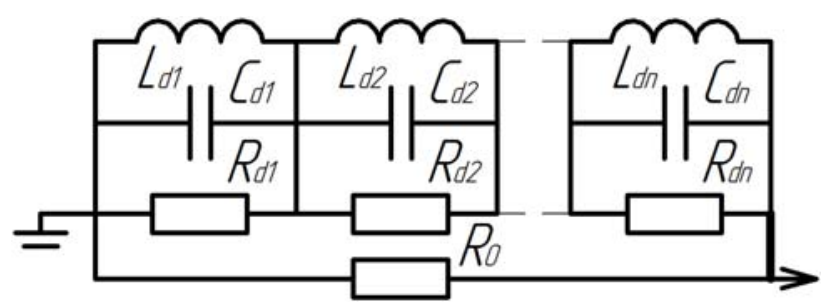

Fig. 6. A schematic diagram of the meter $\left(R_{d}-\right.$ damping resistor)

To achieve the minimum rise time of the transient response $T_{\text {riceTime }}$ it is necessary to choose $R_{d}$ equal to $(\pi / 2) \rho$. If it is necessary to obtain an aperiodic transient response, it is recommended to take $R_{d} \leq \rho$.

The created meter is a coil wounded around a ferromagnetic core of rectangular cross section. The meter's parameters are as follows: coil resistance $2 \Omega$, parasitic capacitance $100 \mathrm{pF}$, inductance $5 \mu \mathrm{H}$.

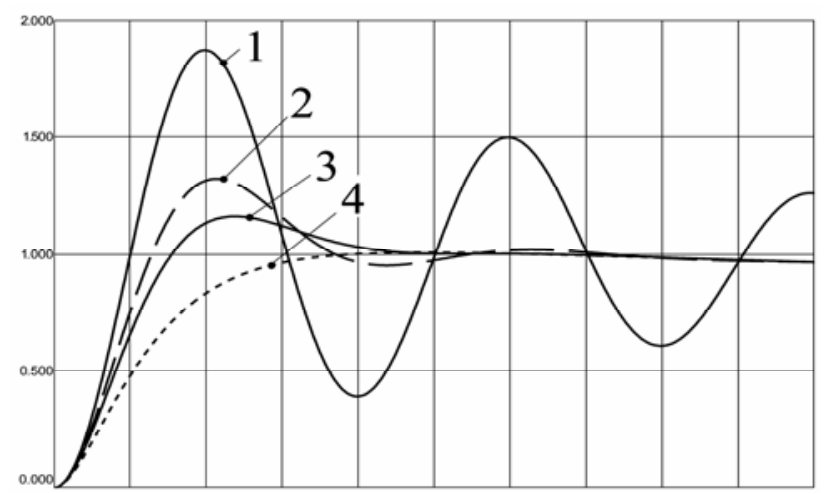

Fig. 7. Results of calculation of the transient response of the meter $\left(1-R_{d}\right.$ is absent; $2-R_{d}=(\pi / 2) \rho ; 3-R_{d}=\rho$;

$4-R_{d}=\rho / 2$; the vertical scale - relative units; the horizontal scale $-5 \mathrm{~ns} /$ cell)

Fig. 8 shows the signal from the meter (2) obtained at measuring the current of rectangular shape (1) with the front of $5 \mathrm{~ns}$. The load resistance $R_{d}$ is taken equal to $(\pi / 2) \rho$.

Fig. 9 shows the waveforms of signals of the sensor and shunt with resistance of $75 \Omega$ installed on the rod lightning receiver. The current of crown is measured.

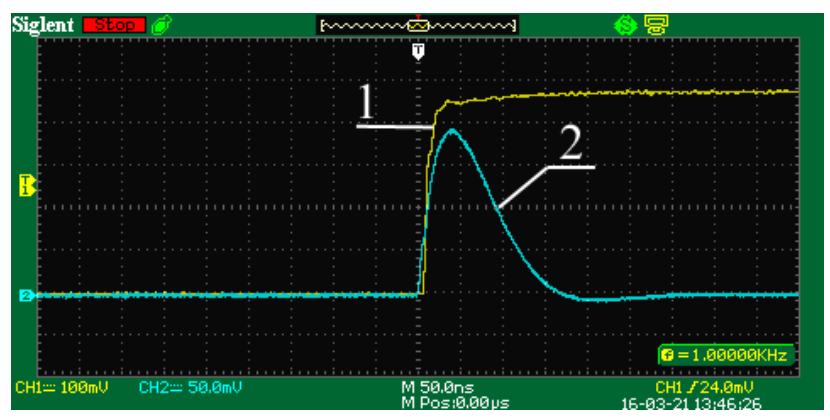

Fig. 8. Waveforms of the output voltage from the meter ( 1 - signal from the generator; 2 - output signal from the meter) 


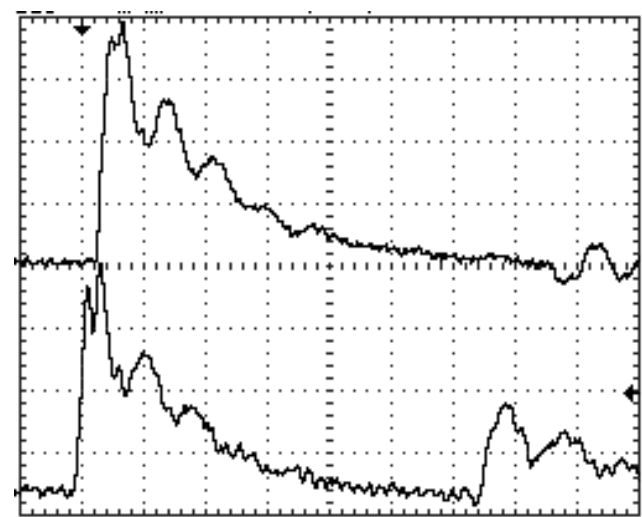

Fig. 9. Waveforms of output voltage signals from the shunt and the meter (channel 1: the vertical scale $100 \mathrm{mV} /$ cell; the horizontal scale $-50 \mathrm{~ns} /$ cell; channel 2: the vertical scale $-20 \mathrm{mV} /$ cell; horizontal scale $-50 \mathrm{~ns} /$ cell)

From Fig. 8: measuring sensitivity $-8 \mathrm{mV} / \mathrm{mA}$, front duration of the output signal $-25 \mathrm{~ns}$.

3. Peculiarities of the sensor's design. Two identical converters connected opposite can be used to increase the sensitivity and noise immunity of the meter. If inductive transducer is loaded to a small resistance, in fact, a short-circuit mode, there is the opposite field close to the largest value of the measured field and displaces the measured magnetic field from volume of the inductive transducer. If one uses two transducers and during the measurements to set them close one to each other, the output signal from the transducers will be substantially less than if they were located relative to each other at a long distance. To solve this problem, there are several ways: the use of small cross-section wires to increase own resistance and, as a result, reduce the current in the coil, or separation of the transducers and removing them from each other until mutual inductance of meters will negligible.

The author thanks Yu.S. Nemchenko for help in the research. The work was carried out in the frame of the project $0115 \mathrm{U} 000611$ funded by the Ministry of Education and Science of Ukraine.

How to cite this article:

Shalamov S.P. An induction sensor for measuring currents of nanosecond range. Electrical engineering \& electromechanics, 2016, no.5, pp. 57-60. doi: 10.20998/2074-272X.2016.5.09.

\section{Conclusions.}

1. A measuring complex is developed for thunderstorm danger warning system which includes an induction transmitter. To increase the sensitivity of the inductiontype sensors a circuit of their serial connection is used. Such a connection of sensors has the property of a long line in the case that the measured field wavelength is comparable to the electrical length of the coil conductor.

2. Calculations of transient response for different values of the electrical parameters of the created sensor elements are carried out.

3. A sample of the induction-type sensor for measuring currents in the nanosecond range is manufactured. Duration of its transient response increase is $25 \mathrm{~ns}$ and sensitivity $-8 \mathrm{mV} / \mathrm{mA}$.

1. Chernuhin A. Yu., Kniaziev V.V. The streamer corona from the rod lightning arresters. East European Scientific Journal, 2016, no.6, iss.2, pp. 39-46. (Rus). V.V. Metrological maintenance operation of high-voltage pulse electric discharge equipment. Bulletin of NTU «KhPI», 2004, no.35, pp. 29-54. (Rus).

3. Shalamov S.P. Measurement of pulsed magnetic fields. Bulletin of NTU «KhPI», 2014, no.50, pp. 161-168. (Rus). magnetic fields. Bulletin of NTU «KhPI», 2007, no.20, pp. 132146. (Rus).

5. Nemchenko Yu.S., Shalamov S.P. Induction converter pulsed magnetic field of lightning. Bulletin of NTU «KhPI», 2015, no.20, pp. 99-108. (Rus).

6. Power Electronic Measurements Ltd (PEM). Available at: http://www.pemuk.com/publications.aspx (Accessed 08 April 2013).

Received 10.09.2016

S.P. Shalamov, Postgraduate Student,

National Technical University «Kharkiv Polytechnic Institute», 21, Kyrpychova Str., Kharkiv, 61002, Ukraine.

phone +38 057 7076010, e-mail: shalamov.stas@i.ua

\section{REFERENCES}

2. Nemchenko Yu.S., Lesnoy I.P., Lantushko B.N, Knyazev

4. Nemchenko Yu.S. Wideband means of measuring pulse 